\title{
Public Perceptions of Deer Management in Scotland
}

\author{
Darragh Hare ${ }^{1,2,3 *}$, Mike Daniels ${ }^{4}$ and Bernd Blossey ${ }^{2}$ \\ ${ }^{1}$ Wildlife Conservation Research Unit, Department of Zoology, The Recanati-Kaplan Centre, Oxford University, Oxford, \\ United Kingdom, ${ }^{2}$ Department of Natural Resources and the Environment, Cornell University, Ithaca, NY, United States, \\ ${ }^{3}$ Center for Conservation Social Sciences, Cornell University, Ithaca, NY, United States, ${ }^{4}$ The John Muir Trust, Pitlochry, \\ United Kingdom
}

\section{OPEN ACCESS}

Edited by:

Camilla Sandström,

Umeå University, Sweden

Reviewed by:

Matthew Grainger, Norwegian Institute for Nature Research (NINA), Norway Christian Kiffner Leibniz Center for Agricultural

Landscape Research (ZALF), Germany

*Correspondence: Darragh Hare darragh.hare@zoo.ox.ac.uk

Specialty section:

This article was submitted to

Human-Wildlife Dynamics, a section of the journal

Frontiers in Conservation Science

Received: 22 September 2021 Accepted: 01 November 2021 Published: 16 December 2021

Citation: Hare D, Daniels M and Blossey B (2021) Public Perceptions of Deer Management in Scotland.

Front. Conserv. Sci. 2:781546. doi: 10.3389/fcosc.2021.781546
In Scotland, large deer populations are associated with negative ecological and socioeconomic impacts, such as damage to peatlands and forests, agricultural and commercial forestry losses, Lyme disease transmission, and road accidents. Increasing the annual deer cull might help address these negative impacts, but could be ethically controversial. A stratified sample of adults living in Scotland $(n=1,002)$ responded to our online questionnaire measuring perceptions of deer management, including the acceptability of increasing the deer cull if doing so would help achieve a variety of ecological and social objectives. Overall, respondents indicated that it would be acceptable to increase the deer cull if doing so would serve public interests by reducing negative impacts of deer, with deer welfare, environmental conservation, and public health and safety being the most relevant ethical considerations. Although rural and urban respondents reported significantly different experiences and perceptions of deer, their values (i.e., attitudes, beliefs, and policy preferences) regarding deer management were very similar. Understanding values of the general public, beyond vocal interest groups, can help inform decisions on contentious wildlife management issues.

Keywords: animal welfare, culling, ecological restoration, ethics, human-wildlife conflict, social acceptability, wildlife governance and institutions

\section{INTRODUCTION}

Scotland has a deer problem. Wild deer are iconic Scottish animals and feature prominently in Scottish culture. However, populations of native red deer (Cervus elaphus) and roe deer (Capreolus capreolus) have expanded in the absence of extirpated major predators such as wolves (Canis lupus), bears (Ursus arctos), and lynx (Lynx lynx). After more than a century of land use strategies to increase deer numbers across much of the country, Scotland is currently home to approximately one million deer. High deer numbers are associated with negative ecological and socioeconomic impacts, such as damage to peatlands and forests, Lyme disease transmission, agricultural and commercial forestry losses, and road accidents (Phillip et al., 2009; Pepper et al., 2019; Scottish Environment LINK, 2020). Moreover, substantial animal welfare implications accompany high deer numbers, with thousands of deer starving each winter and thousands more dying or being injured on roads (Scottish Animal Welfare Commission, 2021).

Concern over ecological and socioeconomic impacts of deer in Scotland is not new (Hobbs, 2009; Davies and White, 2012). For approximately 150 years, successive governments have attempted to establish sustainable deer management institutions, but with limited success (Figure 1). At the root of this inertia lie Scotland's unusual governance arrangements, in which the 
Seven separate governmentappointed inquiries take place over an 80-year period into the 'red deer problem'.

Red deer numbers rise to 180,000 and the Red Deer Commission reports that "the use of land entirely or mainly for deer cannot be justified where only a proportion of the annual recruitment is culled and the balance left to die or spread onto adjacent land."

The new Deer (Scotland) Act 1996 aims to tackle deer damage as part of the implementation in Scotland of the European Habitats Directive.

Red deer numbers reach an all-time high of $\mathbf{4 0 0 , 0 0 0}$ and the Deer Commission is merged with SNH. The outgoing Chair of the Deer Commission says: "The current voluntary system has not evolved much in the last 20 years... if opportunities for reform are not taken then other approaches will need to be considered."

SNH report to the Scottish Government - Deer Management in Scotland says: "We are not confident that present approaches to deer management will be effective in sustaining and improving the natural heritage in a reasonable timescale."

A follow-up SNH report, Assessing Progress in Deer Mangement, says: "In the context of future challenges to land management, (we) recognise the ongoing pace of change required. We highlight the essential role that deer management needs to play in progressing and responding to these challenges.
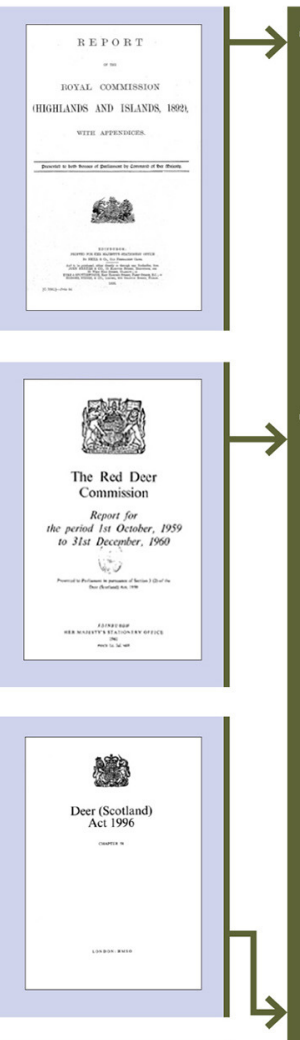

1996

\section{9}

1989

1960

1965

1872

1954
Red Deer Commission set up giving governments power to protect agriculture and forestry from deer damage. It estimates that numbers have reached 150,000 , and insists that "the root of all deer trouble is lack of adequate management."

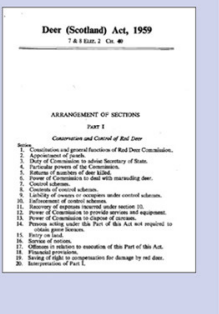

"Thirty years on and no improvement" announces the Red Deer Commission Chairman. "Deer numbers now at $\mathbf{3 0 0 , 0 0 0}$. If we cannot get the required cooperation from deer managers we will have no alternative but to seek a statutory solution to the problems."

Red Deer Commission is replaced by the Deer Commission Scotland to include oversight of roe, fallow and sika. Deer numbers continue to rise over the next decade and beyond.

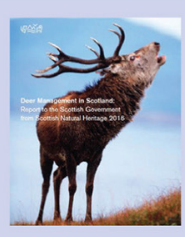

1998

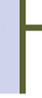

\section{$\rightarrow$}

2010

2014

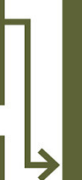

2016

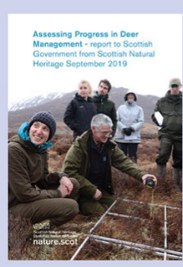

2017

2019
A Land Reform Review Group report to the Scottish Government recommends: "Improvements should be made to the current statutory framework governing the hunting of deer in Scotland to ensure appropriate culls are carried out to adequately safeguard public interests."

FIGURE 1 | Attempts to address persistent problems associated with deer in Scotland for approximately 150 years have achieved limited success. Reproduced with permission from Scottish Environment LINK (2020). 
Scottish Government (SG) has legal responsibility for deer management but private landowners own and control the right to hunt deer on their property (Putman, 2010). In combination with extremely concentrated patterns of landownership in which a few hundred private landowners own more than half of all rural land in Scotland (Glenn et al., 2019), these governance arrangements create opportunities for private and public interests to seriously collide. Many private landowners experience economic and cultural incentives to maintain large deer populations on their land despite deleterious impacts of high deer numbers at larger spatial scales, frustrating efforts to coordinate deer management at landscape levels and excluding many local people from decisions that directly affect them (MacMillan and Leitch, 2008; Davies and White, 2012; Mustin et al., 2017; Glenn et al., 2019). Scotland's deer problem is therefore not a matter of deer biology and ecology but governance arrangements that do not effectively manage trade-offs between multiple societal interests and objectives (Redpath et al., 2015; Ceauşu et al., 2019; Kirkland et al., 2021).

An annual cull of approximately 100,000 deer takes place across public and private land in Scotland. On private sporting estates, which cover large swathes of rural land (Glass et al., 2019), most deer stalking (shooting) is carried out by landowners, their staff, guests, and paying clients (Mustin et al., 2017). Under the "voluntary principle" private landowners set their own cull targets (Putman, 2010). NatureScot (the national public body responsible for enforcing deer legislation) requires some landowners to submit a cull return, and landowners are legally obliged to do so within a statutory period. However, there is no obligation to shoot a particular number of deer, and if landowners do not meet the targets they set themselves, NatureScot sanctions them only in exceptional circumstances. Unlike most other European countries, there is very limited public participation in deer stalking in Scotland. A large proportion of deer stalking therefore happens out of sight of the general public and with very little regulatory oversight (MacMillan and Leitch, 2008; Davies and White, 2012; Pepper et al., 2019).

In 2017, SG commissioned an independent Deer Working Group (DWG) to make recommendations on how to overcome persistent ecological and socioeconomic difficulties associated with deer management. The DWG recommended that SG brings forward new legislation, as well as non-statutory provisions, to safeguard public interests and promote more sustainable deer management (Pepper et al., 2019). In 2021, SG endorsed the DWG's recommendations and pledged to introduce new legislation that would reinforce NatureScot's powers to require reductions in deer populations on both public and private land (Scottish Government, 2021).

In the absence of viable non-lethal methods for controlling deer populations, efforts to address Scotland's deer problem will likely involve increasing the annual deer cull. Shooting more deer might effectively reduce deer numbers and negative impacts, but could potentially be controversial among the Scottish public (Dandy et al., 2011; Martínez-Jauregui et al., 2020), many of whom may be unaware that a deer cull already exists or of the magnitude of negative ecological and socioeconomic impacts associated with large deer populations
(Dandy et al., 2012). Multiple ethical considerations, for example animal welfare, environmental conservation, public health and safety, and social justice, as well as personal experiences and perceptions of deer, could all influence how members of the public perceive the acceptability of increasing the annual cull (Whitefield et al., 2021).

Wildlife policies and programs that lack public acceptability can erode confidence in conservation institutions and are unlikely to succeed in the long run (Bremner and Park, 2007; Decker et al., 2016; Crowley et al., 2017; Pomeranz et al., 2021). Robust, up-to-date data on public perceptions of deer management could therefore help inform decisions regarding the contentious possibility of increasing Scotland's annual deer cull. Previous studies have focused on particular geographic locations or interest groups, finding mixed support for culling to reduce negative impacts of deer, and a general preference for non-lethal measures such as fencing and sterilization (Dandy et al., 2011, 2012; Whitefield et al., 2021). However, no research has specifically investigated public acceptability of increased culling against the contemporary policy backdrop and among a broad sample of the Scottish public, whose perceptions will contribute to the legitimacy of any eventual policies to lethally control deer in the public interest. Moreover, no research has measured the relevance of multiple, possibly competing, ethical considerations to how people think about ecological and socioeconomic dimensions of deer management in Scotland.

We developed an online questionnaire to address these knowledge gaps and produce practically orientated evidence to help inform forthcoming decisions about whether and how to reform deer management in Scotland. We sought to obtain a snapshot of how people living in Scotland think about deer management and deer welfare. Specifically, we asked: How acceptable would it be to increase the deer cull if doing so would help achieve various ecological and socioeconomic objectives (i.e., allow forests to recover, allow peatlands to recover, address climate change by storing more carbon, reduce the number of deer that starve in winter, allow other animals to survive and thrive, reduce the spread of Lyme disease, create more stalking opportunities for people who like to shoot deer, provide free or low-cost venison, and reduce the number of road accidents involving deer)? How important is it that people who shoot deer are local, have formal hunting or stalking qualifications (to ensure that deer die as quickly as possible), or are professional (i.e., hunting or stalking is part of their paid occupation, not a pastime)? How acceptable it would be for people who shoot deer to use parts of the deer in various ways (i.e., keep meat; give meat to friends and family; sell meat; give meat to people in need, such as donating it to a food bank or soup kitchen; or keep parts of deer other than meat, such as heads, skulls, hides, or antlers)? What are respondents' experiences and general perceptions of deer (i.e., how often they see deer; whether they enjoy knowing wild deer live in Scotland; whether they knew there is an annual deer cull in Scotland; and whether they thought deer populations in Scotland were too low, too high, or about right)? To what extent are various ethical considerations (i.e., social justice, deer welfare, welfare of animals other than deer, environmental 
TABLE 1 | Descriptive statistics for overall sample and split by rural and urban respondents.

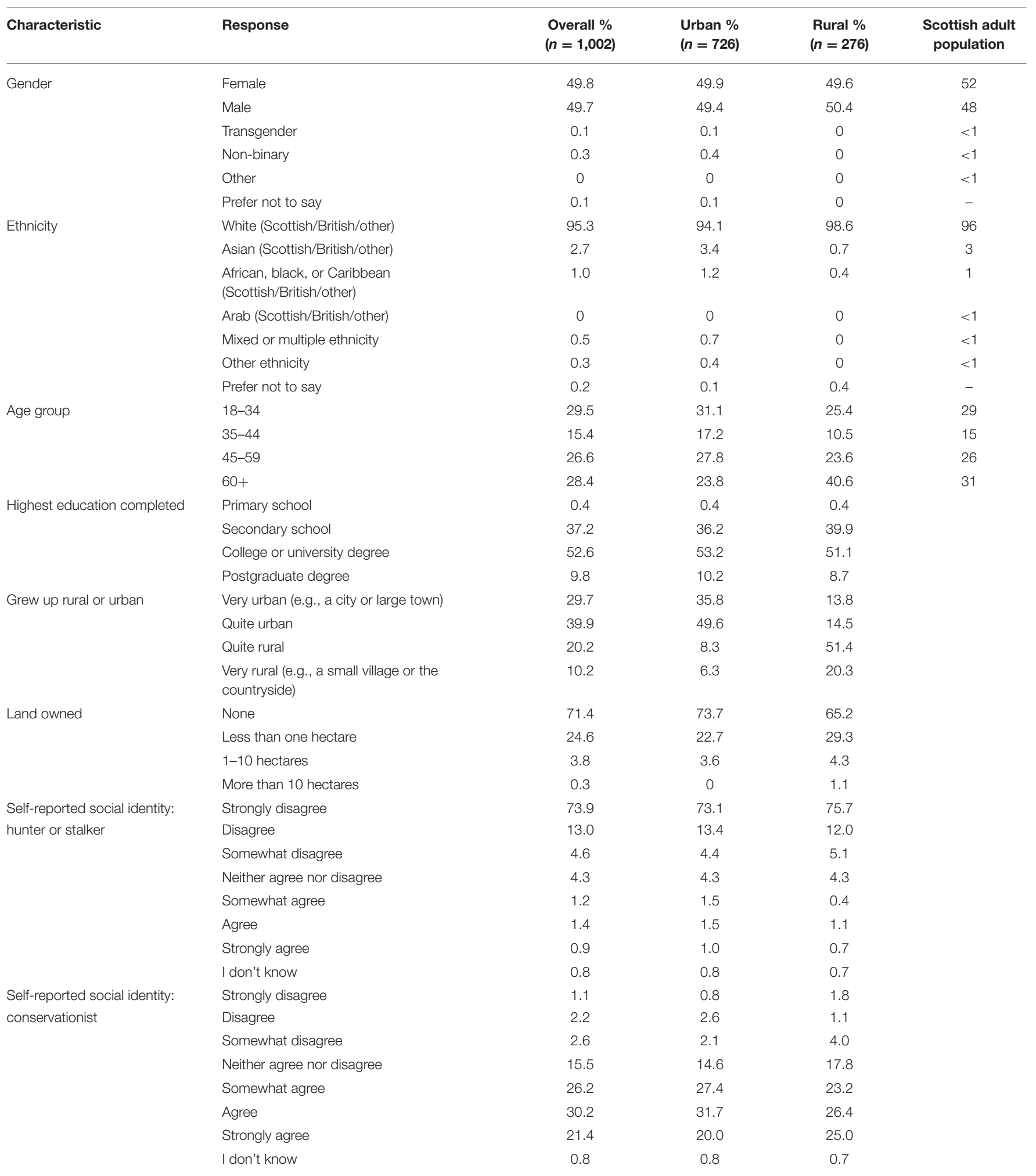


TABLE 1 | Continued

\begin{tabular}{|c|c|c|c|c|c|}
\hline Characteristic & Response & $\begin{array}{l}\text { Overall \% } \\
(n=1,002)\end{array}$ & $\begin{array}{l}\text { Urban \% } \\
(n=726)\end{array}$ & $\begin{array}{l}\text { Rural \% } \\
(n=276)\end{array}$ & $\begin{array}{l}\text { Scottish adult } \\
\text { population }\end{array}$ \\
\hline \multirow{8}{*}{$\begin{array}{l}\text { Self-reported social identity: } \\
\text { animal protectionist }\end{array}$} & Strongly disagree & 1.2 & 1.1 & 1.4 & \\
\hline & Disagree & 1.1 & 1.2 & 0.7 & \\
\hline & Somewhat disagree & 1.7 & 2.1 & 0.7 & \\
\hline & Neither agree nor disagree & 12.7 & 12.5 & 13.0 & \\
\hline & Somewhat agree & 20.2 & 20.0 & 20.7 & \\
\hline & Agree & 32.2 & 32.4 & 31.9 & \\
\hline & Strongly agree & 30.3 & 30.3 & 30.4 & \\
\hline & I don't know & 0.6 & 0.4 & 1.1 & \\
\hline \multirow{6}{*}{$\begin{array}{l}\text { Trusts the scottish government } \\
\text { to make the right decisions }\end{array}$} & Never & 11.6 & 10.5 & 14.5 & \\
\hline & Only now and then & 22.0 & 23.6 & 17.8 & \\
\hline & Some of the time & 35.7 & 35.7 & 35.9 & \\
\hline & Most of the time & 25.3 & 25.0 & 26.4 & \\
\hline & Always & 4.1 & 4.3 & 3.6 & \\
\hline & I don’t know & 1.3 & 1.1 & 1.8 & \\
\hline
\end{tabular}

Proportions of Scottish adult population given for three demographic characteristics used to stratify overall sample: gender, ethnicity, and age.

conservation, and public health and safety) relevant to how people think about deer management? On average, do answers to these questions differ between people who live in rural versus urban areas?

\section{METHODS}

\section{Questionnaire Development}

We designed a questionnaire in conversation with staff from environmental and animal welfare organizations in Scotland and academics with expertise in deer management, conservation social sciences, and animal welfare. This group $(n=14)$ pretested our questionnaire, evaluating it for understandability, balance, accuracy, and relevance to contemporary policy considerations in Scotland. We incorporated group members' comments into the final questionnaire (Supplementary Material) before collecting data.

\section{Sampling and Procedure}

Between 16 March and 20 April 2021, we recruited 1,002 people aged 18 and over living in Scotland via Qualtrics (qualtrics.com) to answer our questionnaire on the Qualtrics survey platform. We minimized sampling error and increased the external validity of our sample (Wardropper et al., 2021) by stratifying it to closely approximate the Scottish adult population in terms of age, ethnicity, and gender identity (Table 1) according to the most recent Scottish Government statistics (Scottish Government, 2019). We deliberately oversampled people living in rural areas to enable more precise rural-urban comparisons.

Respondents first answered a block of demographic questions to ensure they met sample quotas (age, ethnicity, gender identity, and rural/urban residence). Respondents then read a short passage explaining deer management in Scotland, designed to ensure that all respondents, regardless of prior knowledge, had sufficient context to understand and answer subsequent questionnaire items. Using seven-point Likert scales with the additional option of "I don't know," respondents answered blocks of items measuring: how acceptable it would be to shoot more deer if doing so would help achieve various ecological and socioeconomic objectives; how important it is that people who shoot deer have particular characteristics; and how acceptable it would be for people who shoot deer to use meat and other deer parts in various ways. Respondents used four-point ordinal scales to answer a block of items measuring the relevance of multiple ethical considerations when responding to previous blocks, and a combination of ordinal scales and seven-point Likert scales to answer a block of items measuring their experiences and general perceptions of deer. Respondents finished by providing information on additional demographic characteristics and social identities.

To prevent priming effects, we randomized the order of items within all blocks, as well as the order in which respondents received blocks of items measuring acceptability of shooting more deer, characteristics of people who shoot deer, and acceptability of using meat and other deer parts (Supplementary Material). All respondents provided informed consent. Our study was reviewed by and received ethics clearance through the University of Oxford Central University Research Ethics Committee (reference R74567/RE001) and Cornell University Institutional Review Board for Human Participants (protocol 2103010182).

\section{Data Analysis}

We analyzed data using R (R Development Core Team, 2008) and considered $p<0.05$ statistically significant. For rural-urban comparisons, we combined respondents who reported living in 


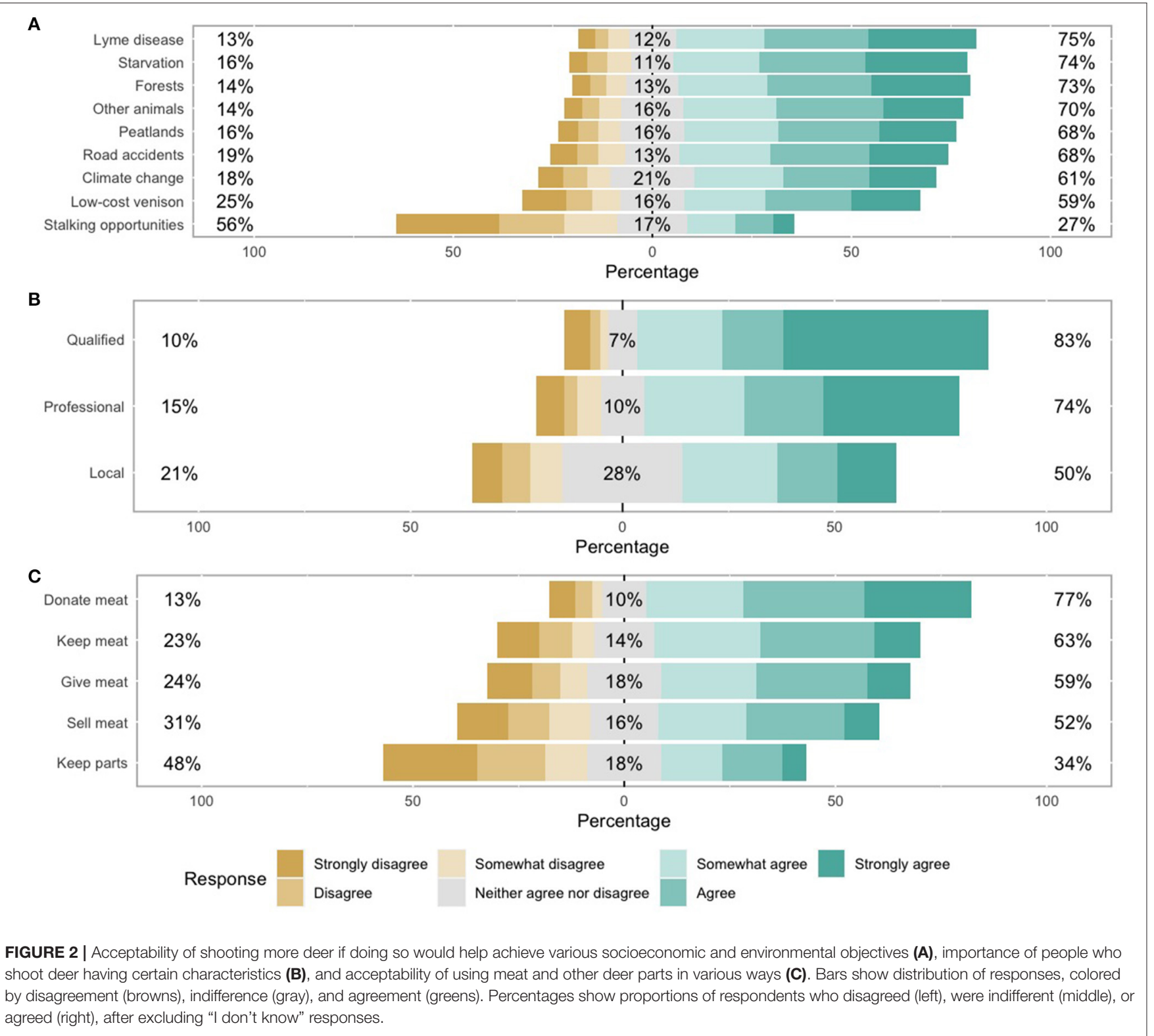

very urban $(n=292)$ and quite urban $(n=434)$ locations into a single urban residence category $(n=726)$, and respondents who reported living in very rural $(n=77)$ and quite rural ( $n$ $=199$ ) locations into a single rural residence category $(n=$ 276). We used the "likert" package (Bryer and Speerschneider, 2016) to calculate and visualize percentages of responses, after removing "I don't know" answers, for items on acceptability of shooting more deer, importance of people who shoot deer having particular characteristics, and acceptability of using deer parts in various ways.

We used the "ordinal" package (Christensen, 2019) to run separate ordinal logistic regression models testing for differences between rural and urban responses to all items measuring: the acceptability of shooting more deer; the importance of people who shoot deer having particular characteristics; the acceptability of using deer parts in various ways; and respondents' experiences and general perceptions of deer. All models had a single binary predictor variable representing rural or urban residence.

We transformed ordinal scale responses for items measuring relevance of ethical considerations into numeric values $(0=$ not at all relevant, $1=$ somewhat relevant, $2=$ relevant, and 3 $=$ very relevant). We used $t$-tests to compare urban and rural responses for each ethical consideration. We used $t$-tests to compare differences in mean values between all pairs of ethical considerations, applying Bonferroni corrections to account for multiple comparisons (i.e., $p<0.005$ ). For all $t$-tests we removed "I don't know" responses. 


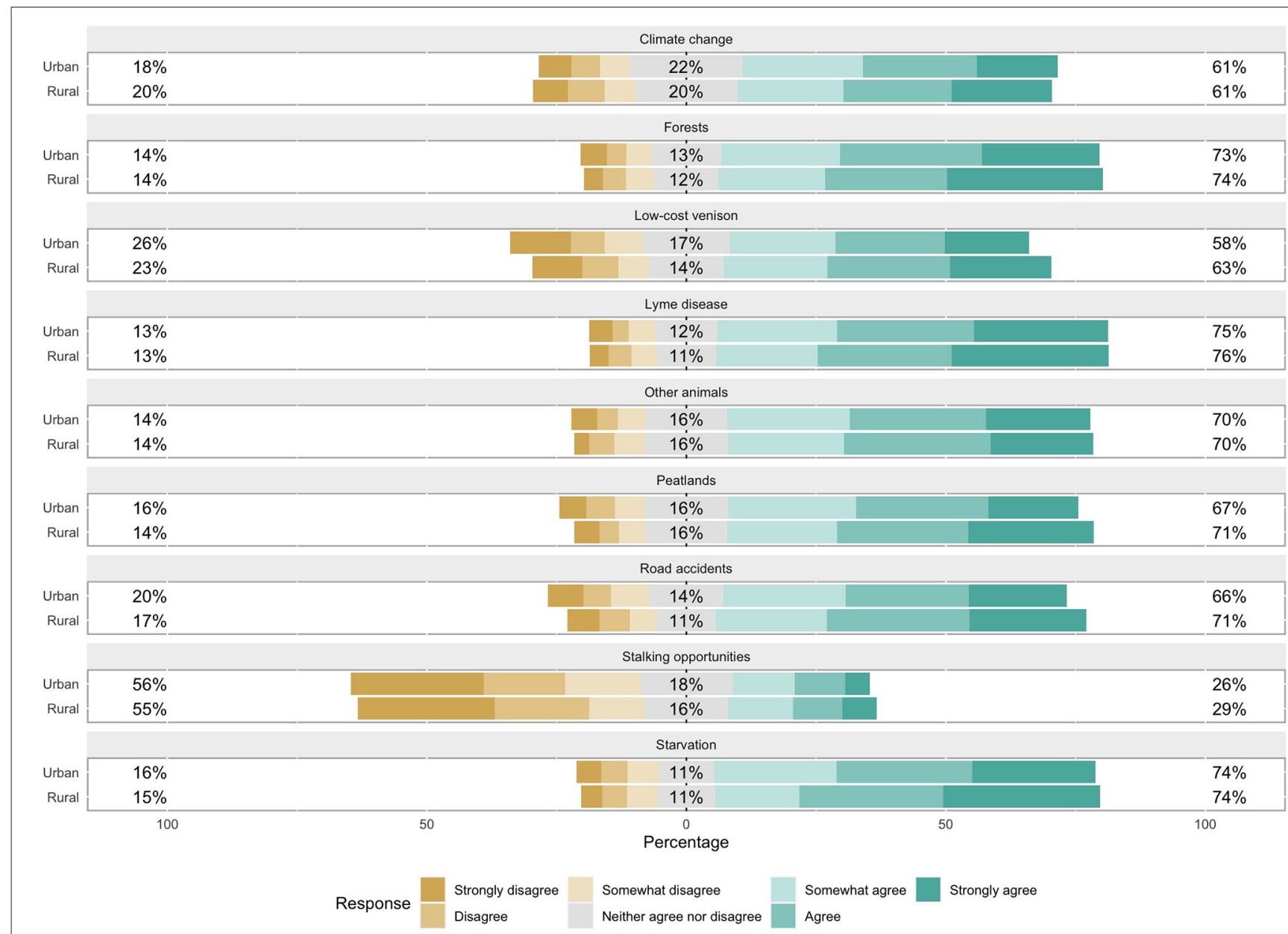

FIGURE 3 | Acceptability of shooting more deer if doing so would achieve various socioeconomic and environmental objectives, split by urban and rural respondents. Bars show distribution of responses, colored by disagreement (browns), indifference (gray), and agreement (greens). Percentages show proportions of respondents who disagreed (left), were indifferent (middle), or agreed (right) that it would be acceptable to shoot more deer if doing so would achieve each objective, after excluding "I don't know" responses.

\section{RESULTS}

A majority of respondents indicated (i.e., somewhat agreed, agreed, or strongly agreed) it would be acceptable to shoot more deer if doing so would reduce the spread of Lyme disease (75\%); reduce the number of deer that starve in winter (74\%); allow forests to recover (73\%); allow other animals to survive and thrive (70\%); allow peatlands to recover (68\%); reduce road accidents (68\%); address climate change by storing more carbon (61\%); and provide free or low-cost venison (59\%) (Figure 2). The only objective a majority (56\%) of respondents indicated would not be acceptable (i.e., somewhat disagreed, disagreed, or strongly disagreed that it would be acceptable) was to create more stalking opportunities for people who like to shoot deer (Figure 2).

We found no significant differences between rural and urban responses to items measuring acceptability of shooting more deer to reduce the spread of Lyme disease, allow forests to recover, allow other animals to survive and thrive, reduce road accidents, address climate change by storing more carbon, provide free or low-cost venison, or create more stalking opportunities for people who like to shoot deer (Figure 3; ordinal logistic regression models, all $p$-values $\geq 0.06$ ). We found significant differences between rural and urban responses to items measuring acceptability of shooting more deer to reduce the number of deer that starve in winter $(z=-1.99, p=0.047)$ and to allow peatlands to recover $(z=-2.1, p=0.036)$. Rural people were more likely than urban people to strongly agree that both objectives were acceptable.

A majority of respondents indicated it would be important that individuals who shoot deer have formal hunting or stalking qualifications (83\%); are professional (74\%); and are local (50\%) (Figure 2). We found no significant differences between rural and urban responses to any items in this block (Figure 4; ordinal logistic regression models, all $p$-values $\geq 0.23$ ).

A majority of respondents indicated it would be acceptable for people who shoot deer to donate meat to people in need (77\%); keep meat (63\%), give meat to friends and family (59\%), and sell meat (52\%) (Figure 2). Acceptability of keeping parts of 

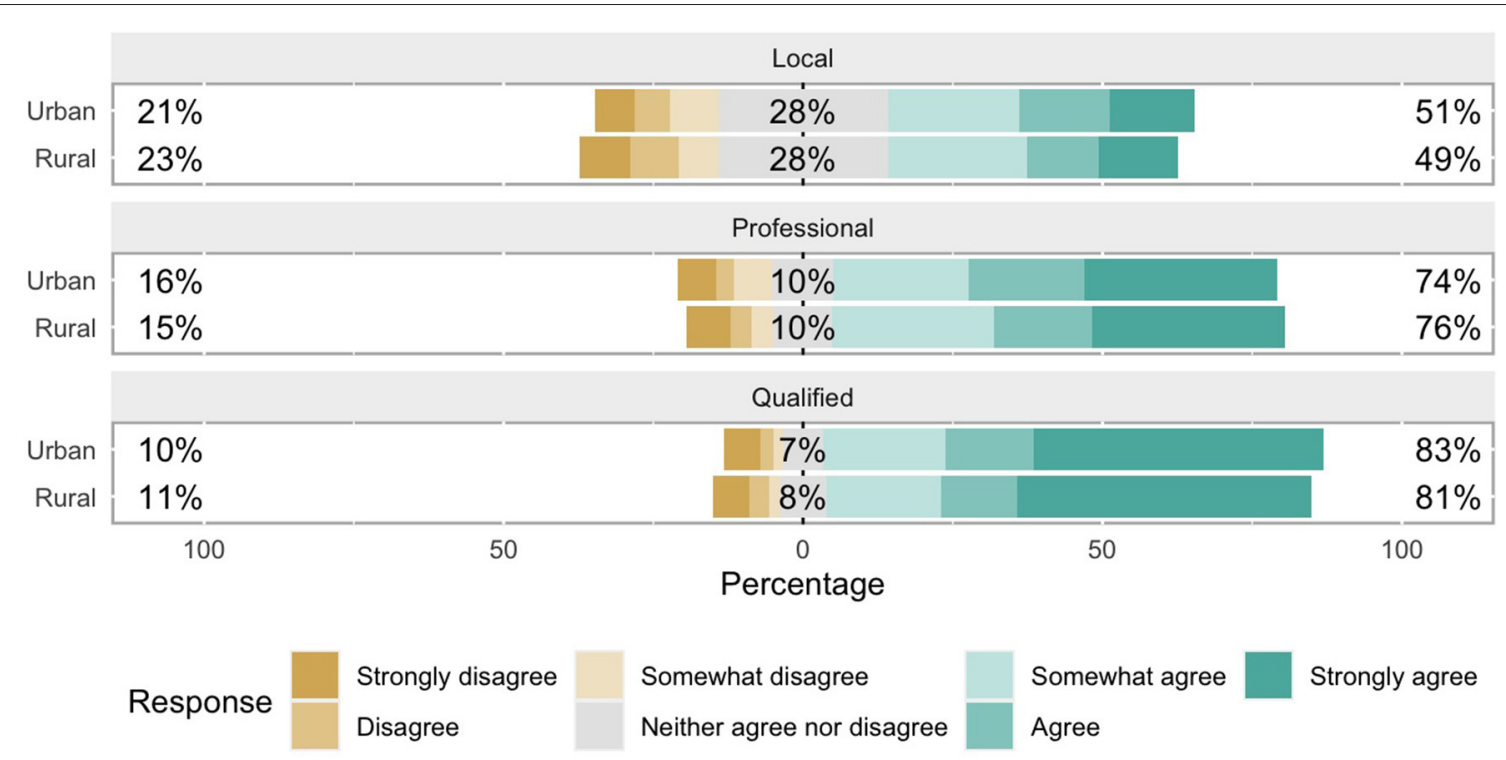

FIGURE 4 | Importance of people who shoot deer having certain characteristics, split by urban and rural respondents. Bars show distribution of responses, colored by disagreement (browns), indifference (gray), and agreement (greens). Percentages show proportions of respondents who disagreed (left), were indifferent (middle), or agreed (right) that each characteristic was important, after excluding "I don't know" responses.

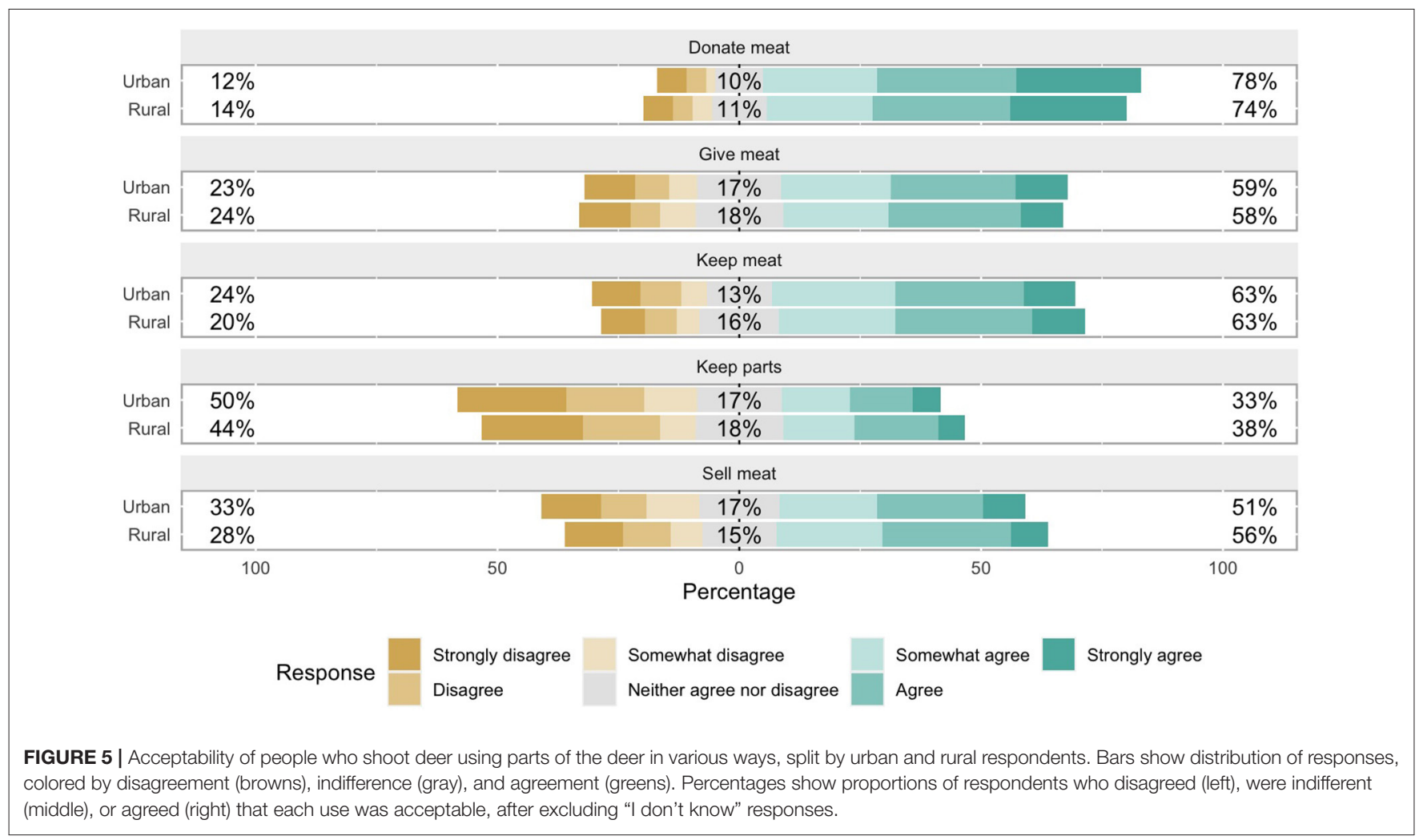

deer other than meat, such as heads, skulls, hides, or antlers was much lower: $34 \%$ of respondents agreed, $48 \%$ disagreed, and $18 \%$ neither agreed nor disagreed this would be acceptable. We found no significant differences between rural and urban responses to any items in this block (Figure 5; ordinal logistic regression models, all $p$-values $\geq 0.20$ ).

The most relevant ethical considerations were deer welfare $(M$ $=2.31, S D=0.87)$, environmental conservation $(M=2.25, S D$ 


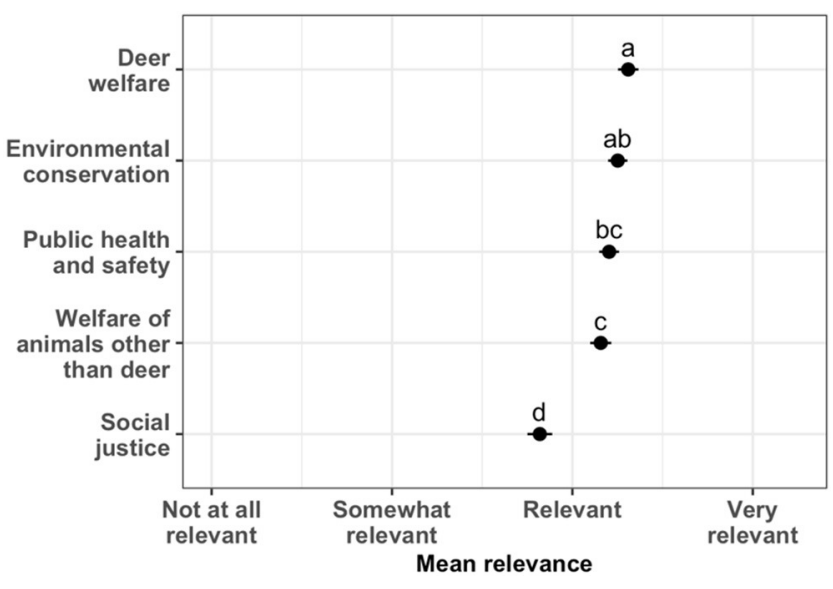

FIGURE 6 | Mean relevance of ethical considerations while responding to items on acceptability of shooting more deer, importance of people who shoot deer having certain characteristics, and acceptability of using meat and other deer parts in various ways. Points represent mean values after transforming responses from categories displayed on the $\mathrm{x}$-axis into numerical values ranging from 0 (not at all relevant) to 3 (very relevant) and removing "I don't know" responses. Error bars represent two standard errors of the mean. Considerations that share letters are not significantly different after Bonferroni correction (i.e., $p<0.005$ ).
$=0.82)$, and public health and safety $(M=2.20, S D=0.85)$. The least relevant ethical consideration was social justice $(M=$ $1.82, S D=1.04$ ) (Figure 6). After Bonferroni correction, deer welfare was not significantly more relevant than environmental conservation $\left[t_{(1859.9)}=1.49, p=0.137\right]$ or public health and safety $\left[t_{(1876.0)}=2.67, p=0.008\right]$, but was significantly more relevant than welfare of animals other than deer $\left[t_{(1847.1)}=\right.$ $3.73, p<0.001]$, and social justice $\left[t_{(1754.1)}=11.00, p<0.001\right]$. Environmental conservation was not significantly more relevant than public health and safety $\left[t_{(1892.3)}=1.24, p=0.214\right]$ or welfare of animals other than deer $\left[t_{(1845.0)}=2.38, p=0.017\right]$, but was significantly more relevant than social justice $\left[t_{(1716.0)}=\right.$ 9.91, $p<0.001]$. Public health and safety was not significantly more relevant than welfare of animals other than deer $\left[t_{(1864.4)}=\right.$ $1.15, p=0.249$ ], but was significantly more relevant than social justice $\left[t_{(1749.0)}=8.69, p<0.001\right]$. Welfare of animals other than deer was significantly more relevant than social justice $\left[t_{(1769.3)}\right.$ $=7.47, p<0.001]$. We found no significant differences between rural and urban responses to any items in this block ( $t$-tests, all $p$-values $\geq 0.11$ ).

Rural and urban respondents' experiences and general perceptions of deer differed significantly (Table 2). Overall, respondents reported enjoying knowing that wild deer live in Scotland, with a higher proportion of people from rural areas strongly agreeing and a higher proportion of people from urban areas agreeing or somewhat agreeing. Compared to urban respondents, rural respondents reported seeing deer more frequently, being more aware that an annual deer cull took place, and being more likely to think that the deer population was too high or far too high.

\section{DISCUSSION}

Our results suggest that it would be acceptable to increase the annual deer cull in Scotland as long as doing so would help serve broad public interests by reducing negative impacts of deer (Figure 2), while ensuring that deer welfare, environmental conservation, and public health and safety receive adequate consideration (Figure 6). These findings echo studies from Spain (Martínez-Jauregui et al., 2020) and the United States (Johnson and Horowitz, 2014; Vayer et al., 2021) documenting support for killing deer to reduce ecological degradation. Moreover, our results show that negative socioeconomic impacts feature at least as prominently as negative ecological impacts in acceptability of reducing high deer populations (Figure 2).

However, not all aspects of shooting more deer were acceptable. Even though we deliberately chose not to use these specific terms, recreational hunting (i.e., creating more stalking opportunities for people who like to shoot deer) and trophy hunting (i.e., keeping parts of the deer other than meat) were the least acceptable in their blocks (Figures 2, 3, 5). Our finding that recreational hunting is less acceptable than other objectives might reflect the absence of a public hunting culture in Scotland, evident in the very small proportions of rural and urban respondents who identify as hunters or stalkers (Table 1). Our finding that trophy hunting is less acceptable than hunting for meat mirrors results from the United States (Responsive Management, 2019; Vayer et al., 2021). Taken together, these findings indicate that public acceptability of killing wild animals depends on motivations of people who kill animals and how they use animal parts.

Long-term justification for any decision to increase the deer cull based on social acceptability will require strong evidence that doing so does in fact serve broad public interests (Bremner and Park, 2007; Crowley et al., 2017). This will require developing ecological assessment metrics that are scientifically defensible and accessible enough to gauge impacts of increased deer culls (Blossey et al., 2019), as well as developing metrics to monitor social acceptability of deer management policies and programs over time. These metrics could contribute to a fair, transparent, adaptive system of setting, monitoring, evaluating, and reporting progress toward ecological and socioeconomic objectives at local and landscape scales (Kirkland et al., 2021).

To be successful, any such system would depend on public and private landowners collecting assessment data to allow evaluation and adaptation. Many landowners already intensively lethally control deer on their properties to reduce deleterious impacts, so would likely willingly contribute assessment data. These include public landowners who manage land mostly for woodland objectives, as well as environmental NGOs, private individuals, and community landowners who manage land for conservation. However, owners of traditional sporting estates may be more reluctant to participate (MacMillan and Leitch, 2008; Glass et al., 2019). This reluctance could spring from tensions between private and public interests but also because some sporting estate owners may be hostile to the aims of conservation organizations, which they perceive to threaten their traditions and with whom they might have a history of 
TABLE 2 | Experiences and general perceptions of deer, and relevance of ethical considerations for overall sample and split by rural and urban respondents.

\begin{tabular}{|c|c|c|c|c|c|c|}
\hline Item & Response & $\begin{array}{l}\text { Overall \% } \\
(n=1,002)\end{array}$ & $\begin{array}{l}\text { Urban \% } \\
(n=726)\end{array}$ & $\begin{array}{l}\text { Rural \% } \\
(n=276)\end{array}$ & $\mathbf{z}$ & $p$ \\
\hline \multirow[t]{8}{*}{ I enjoy knowing wild deer live in Scotland } & Strongly disagree & 0.9 & 0.6 & 1.8 & -2.53 & 0.01 \\
\hline & Disagree & 0.4 & 0.6 & 0.0 & & \\
\hline & Somewhat disagree & 0.6 & 0.8 & 0.0 & & \\
\hline & Neither agree nor disagree & 5.8 & 5.9 & 5.4 & & \\
\hline & Somewhat agree & 11.0 & 12.4 & 7.2 & & \\
\hline & Agree & 30.9 & 31.8 & 28.6 & & \\
\hline & Strongly agree & 49.8 & 47.5 & 55.8 & & \\
\hline & I don't know & 0.6 & 0.4 & 1.1 & & \\
\hline \multirow[t]{6}{*}{ How often do you see deer in Scotland? } & Never or almost never & 15.8 & 19.0 & 7.2 & -6.43 & $<0.001$ \\
\hline & About once a year & 31.6 & 34.2 & 25.0 & & \\
\hline & About once a month & 30.0 & 27.3 & 37.3 & & \\
\hline & About once a week & 12.9 & 11.2 & 17.4 & & \\
\hline & More than once a week & 7.4 & 5.9 & 11.2 & & \\
\hline & I don't know & 2.3 & 2.5 & 1.8 & & \\
\hline \multirow{8}{*}{$\begin{array}{l}\text { Before taking part in this study, I knew that deer } \\
\text { were shot for population management (culled) in } \\
\text { Scotland every year. }\end{array}$} & Strongly disagree & 9.0 & 9.9 & 6.5 & -4.10 & $<0.001$ \\
\hline & Disagree & 9.0 & 8.8 & 9.4 & & \\
\hline & Somewhat disagree & 6.6 & 7.2 & 5.1 & & \\
\hline & Neither agree nor disagree & 10.3 & 10.9 & 8.7 & & \\
\hline & Somewhat agree & 19.2 & 21.1 & 14.1 & & \\
\hline & Agree & 24.1 & 23.1 & 26.4 & & \\
\hline & Strongly agree & 19.3 & 16.0 & 27.9 & & \\
\hline & I don't know & 2.7 & 3.0 & 1.8 & & \\
\hline \multirow{6}{*}{$\begin{array}{l}\text { Before taking part in this study, I thought the } \\
\text { number of deer in Scotland was... }\end{array}$} & Far too low & 2.9 & 3.4 & 1.4 & -3.83 & $<0.001$ \\
\hline & Too low & 9.7 & 10.2 & 8.3 & & \\
\hline & About right & 42.8 & 44.6 & 38.0 & & \\
\hline & Too high & 20.8 & 19.8 & 23.2 & & \\
\hline & Far too high & 3.8 & 2.1 & 8.3 & & \\
\hline & I don't know & 20.1 & 19.8 & 20.7 & & \\
\hline
\end{tabular}

Test statistics (z-values) and p-values are from ordinal logistic regression models testing for differences between rural and urban responses.

conflict (MacMillan et al., 2010). Understanding the extent to which traditional sporting estate owners would be willing to participate in culling, monitoring, and evaluation, should be a priority for research into the feasibility of increasing the deer cull. Participation of sporting estates would be especially important because, in the absence of a public hunting culture, professional deer stalkers, many of whom work for private landowners, would have to continue to carry out the majority of culling.

Considerations of deer welfare were relevant while respondents answered questionnaire items on whether to shoot more deer, which people should shoot more deer, and how those people could use deer parts (Figures 2, 4, 6). But other ethical considerations also mattered. Although deer welfare, environmental conservation, and public health and safety were the most relevant ethical considerations, welfare of animals other than deer and social justice were also relevant (Figure 6). Even the least relevant ethical consideration, social justice, was on average closer to being "very relevant" than "not at all relevant." This finding reinforces the socioecological complexity of deer management, and may help explain why it can be so contentious: it draws together multiple, possibly competing, ethical considerations as well as multiple, possibly competing, wildlife management objectives (Redpath et al., 2015).

Overall support for increasing the deer cull (Figure 2) despite high relevance of deer welfare considerations (Figure 6) could indicate that respondents recognized that desirable public benefits are only achievable by shooting more deer. Alternatively, this finding might indicate that respondents see culling as less concerning in terms of deer welfare than perpetuating a situation in which large numbers starve over winter, or die or get injured in road accidents. Future studies could investigate more precisely how members of the public trade off potentially competing ethical considerations, and whether they believe the welfare implications of culling are more or less ethically acceptable than those of maintaining high deer numbers.

Understanding public perceptions and values (i.e., attitudes, beliefs, and policy preferences) is just one part of the much larger challenge of designing sustainable institutions to address Scotland's deer problem. A major component of that challenge will be to overcome or attenuate enduring tensions between private and public interests, which are mired in a long and deep history of conflicts that include, but extend far beyond, deer 
management (Hobbs, 2009; Phillip et al., 2009; MacMillan et al., 2010). Clearly delineating the fault lines in these conflicts will be essential to overcoming them.

Our results suggest that rural versus urban location is a poor predictor of contemporary values about deer management in Scotland. We found significant differences between rural and urban respondents' experiences and general perceptions of deer, with rural people reporting seeing deer more frequently, having greater knowledge that an annual cull takes place, and thinking the number of deer was too high or far too high (Table 2). This is unsurprising because many of the effects of high deer populations occur most acutely in rural areas, as do most deer management activities (Pepper et al., 2019). However, despite these differences in experiences and perceptions of deer, we found no significant differences between rural and urban respondents' attitudes regarding the importance of people who shoot deer having certain characteristics, the acceptability of using deer parts in various ways, or the relevance of various ethical considerations to their thinking about these topics. We found no significant differences between rural and urban respondents' responses to seven of the nine items measuring acceptability of shooting more deer. Although acceptability of shooting more deer to allow peatlands to recover and to reduce the number of deer that starve over winter were statistically significantly different between rural and urban respondents, the magnitude of those differences was slight (Figure 3). These findings are consistent with Whitefield's et al. (2021) recent study showing that attitudes toward deer management are remarkably similar between urban and rural people in Stirlingshire, an administrative region in central Scotland. In combination, these findings cast doubt, at least regarding deer management in Scotland, on the common expectation in conservation science and practice that urban and rural values regarding wildlife are substantially different.

Our study illustrates the value of sampling from the general public to obtain a more panoramic understanding of how people think about contentious wildlife decisions than would be possible from listening exclusively to representations from vocal special interest groups. Data on values of members of the public who do not typically express an interest in wildlife could be especially useful to public wildlife authorities seeking to incorporate a broader range of public values into their policies and programs (Decker et al., 2016; Giacomelli et al., 2019), or seeking to communicate justifications for contentious decisions to the public. Approximately $20 \%$ of respondents in both rural and urban areas answered "I don't know" to the item measuring their perceptions of the number of deer in Scotland prior to taking part in the study (Table 2), suggesting that members of the general public are not fully aware of Scotland's deer problem. Future research could assess the extent to which people from different groups understand the deer problem, and employ different sampling frames to investigate whether the patterns in values we identified in this study apply more generally. All respondents read a short passage at the beginning of our questionnaire to provide context on deer management in Scotland (Supplementary Material). Future research could also test whether respondents who receive no context, or who receive different types of context, express similar values.
Overall, our results suggest that people in Scotland would like deer management to produce better outcomes for people, deer, and the environment more generally. By providing a snapshot of how a diverse, stratified sample of adults living in Scotland think about deer management and deer welfare against the contemporary policy backdrop, our results could help inform contentious forthcoming decisions on reform toward more sustainable deer management institutions (Pepper et al., 2019; Scottish Government, 2021). Institutions will be more sustainable if they are built upon transparent ecological and socioeconomic objectives, accurately measure and report progress toward meeting those objectives, and are flexible enough to adapt to ecological and socioeconomic differences between places and changes over time (Ceauşu et al., 2019; Kirkland et al., 2021).

\section{DATA AVAILABILITY STATEMENT}

The data supporting the conclusions of this article will be made available by the authors, without undue reservation.

\section{ETHICS STATEMENT}

The studies involving human participants were reviewed and approved by University of Oxford Central University Research Ethics Committee Cornell University Institutional Review Board for Human Participants. The participants provided their informed consent to participate in this study.

\section{AUTHOR CONTRIBUTIONS}

$\mathrm{DH}$ and $\mathrm{MD}$ conceived of the study. $\mathrm{DH}, \mathrm{MD}$, and $\mathrm{BB}$ contributed to questionnaire development. $\mathrm{DH}$ analyzed data and drafted the manuscript. $\mathrm{MD}$ and $\mathrm{BB}$ contributed to manuscript revision. All authors approved the submitted version.

\section{FUNDING}

This work was funded by Scottish Environment LINK Discretionary Project Funding (planning, data collection, and analysis) and the John Muir Trust (data collection).

\section{ACKNOWLEDGMENTS}

We are grateful to colleagues who helped develop and pre-test our questionnaire and 1002 people living in Scotland who completed the questionnaire online.

\section{SUPPLEMENTARY MATERIAL}

The Supplementary Material for this article can be found online at: https://www.frontiersin.org/articles/10.3389/fcosc. 2021.781546/full\#supplementary-material

Supplementary Material | Includes the full questionnaire and a diagram of questionnaire flow. 


\section{REFERENCES}

Blossey, B., Curtis, P., Boulanger, J., and Dávalos, A. (2019). Red oak seedlings as indicators of deer browse pressure: gauging the outcome of different white-tailed deer management approaches. Ecol. Evol. 9, 13085-13103. doi: 10.1002/ece3.5729

Bremner, A., and Park, K. (2007). Public attitudes to the management of invasive non-native species in Scotland. Biol. Conserv. 139, 306-314. doi: 10.1016/j.biocon.2007.07.005

Bryer, J., and Speerschneider, K. (2016). Analysis and Visualization Likert Items. Available online at: https://cran.r-project.org/web/packages/likert/likert.pdf (accessed September 22, 2021).

Ceauşu, S., Graves, R. A., Killion, A. K., Svenning, J. C., and Carter, N. H. (2019). Governing trade-offs in ecosystem services and disservices to achieve humanwildlife coexistence. Conserv. Biol. 33, 543-553. doi: 10.1111/cobi.13241

Christensen, R. B. L. (2019). Ordinal: Regression Models for Ordinal Data. CRAN.

Crowley, S. L., Hinchliffe, S., and McDonald, R. A. (2017). Conflict in invasive species management. Front. Ecol. Environ. 15, 133-141. doi: 10.1002/fee.1471

Dandy, N., Ballantyne, S., Moseley, D., Gill, R., Peace, A., and Quine, C. (2011). Preferences for wildlife management methods among the peri-urban public in Scotland. Eur. J. Wildl. Res. 57, 1213-1221. doi: 10.1007/s10344-011-0534-x

Dandy, N., Ballantyne, S., Moseley, D., Gill, R., Quine, C., and van der Wal, R. (2012). Exploring beliefs behind support for and opposition to wildlife management methods: a qualitative study. Eur. J. Wildl. Res. 58, 695-706. doi: 10.1007/s10344-012-0619-1

Davies, A. L., and White, R. M. (2012). Collaboration in natural resource governance: reconciling stakeholder expectations in deer management in Scotland. J. Environ. Manage. 112, 160-169. doi: 10.1016/j.jenvman.2012.07.032

Decker, D. J., Smith, C. A., Forstchen, A. B., Hare, D., Pomeranz, E. F., DoyleCapitman, C., et al. (2016). Governance principles for wildlife conservation in the 21st century. Conserv. Lett. 9, 290-295. doi: 10.1111/conl.12211

Giacomelli, S., Hare, D., Blossey, B., and Gibbert, M. (2019). Public trust thinking and public ownership of wildlife in Italy and the United States. Environ. Policy Gov. 29, 209-219. doi: 10.1002/eet.1848

Glass, J., McMorran, R., and Thomson, S. (2019). The Effects Associated With Concentrated and Large Scale Land Ownership in Scotland: A Research Review. Scottish Land Commission. Available online at: https:/landcommission. gov.scot/wp-content/uploads/2019/03/Research-Review-ConcentratedOwnership-FINAL-20190320.pdf (accessed September 22, 2021).

Glenn, S., MacKessack-Leitch, J., Glass, J., and McMorran, R. (2019). Investigation Into the Issues Associated With Large Scale and Concentrated Landownership in Scotland. Inverness: Scottish Land Commission. Available online at: https:// www.landcommission.gov.scot/downloads/5dd7d6fd9128e_InvestigationIssues-Large-Scale-and-Concentrated-Landownership-20190320.pdf (accessed September 22, 2021).

Hobbs, R. (2009). Woodland restoration in Scotland: ecology, history, culture, economics, politics and change. J. Environ. Manage. 90, 2857-2865. doi: 10.1016/j.jenvman.2007.10.014

Johnson, B. B., and Horowitz, L. S. (2014). Beliefs about ecological impacts predict deer acceptance capacity and hunting support. Soc. Nat. Resour. 27, 915-930. doi: 10.1080/08941920.2014.905887

Kirkland, H., Daniels, M., Rao, S., Krofel, M., Blossey, B., Chapman, T., et al. (2021). Defining and evaluating success in deer management in Scotland. Front. Conserv. Sci. doi: 10.3389/fcosc.2021.770303

MacMillan, D. C., and Leitch, K. (2008). Conservation with a gun: understanding landowner attitudes to deer hunting in the Scottish Highlands. Hum. Ecol. 36, 473-484. doi: $10.1007 / \mathrm{s}$

MacMillan, D. C., Leitch, K., Wightman, A., and Higgins, P. (2010). The management and role of highland sporting estates in the early twenty-first century: the owner's view of a unique but contested form of land use. Scottish Geogr. J. 126, 24-40. doi: 10.1080/14702540903499124

Martínez-Jauregui, M., Delibes-Mateos, M., Arroyo, B., and Soliño, M. (2020). Addressing social attitudes toward lethal control of wildlife in national parks. Conserv. Biol. 34, 868-878. doi: 10.1111/cobi.13468

Mustin, K., Newey, S., and Slee, B. (2017). Towards the construction of a typology of management models of shooting opportunities in Scotland. Scottish Geogr. J. 133, 214-232. doi: 10.1080/14702541.2017.1406133

Pepper, S., Barbour, A., and Glass, J. (2019). The Management of Wild Deer in Scotland: Report of the Deer Working Group. Edinburgh: The
Scottish Government Available at: Available online at: https://www.gov.scot/ publications/management-wild-deer-scotland/pages/5/ (accessed September 22, 2021).

Phillip, S., Dandy, N., Gill, R., and MacMillan, D. C. (2009). Is legislation a barrier to the sustainable management of game species? A case study of wild deer in Britain. J. Environ. Plan. Manag. 52, 993-1012. doi: 10.1080/09640560903327351

Pomeranz, E. F., Hare, D., Smith, C. A., Forstchen, A. B., Schiavone, M. V., Jacobson, C. A., et al. (2021). Successful wildlife conservation requires good governance. Front. Conserv. Sci. 2:753289. doi: 10.3389/fcosc.2021.753289

Putman, R. (2010). "A review of the various legal and administrative systems governing management of large herbivores in Europe," in Ungulate Management in Europe: Problems and Practices, eds R. Putman, M. Apollonio, and R. Andersen (Cambridge: Cambridge University Press), 54-79. Available online at: http://www.cabdirect.org/abstracts/20113262821. html (accessed September 22, 2021).

R Development Core Team. (2008). R: A Language and Environment for Statistical Computing. Available online at: http://www.r-project.org (accessed September 22, 2021).

Redpath, S. M., Bhatia, S., and Young, J. (2015). Tilting at wildlife: reconsidering human-wildlife conflict. Oryx 49, 222-225. doi: 10.1017/S0030605314000799

Responsive Management. (2019). Americans' Attitudes Toward Hunting, Fishing, Sports Shooting and Trapping. Harrisonburg, VA.

Scottish Animal Welfare Commission (2021). Report on The Management of Wild Deer in Scotland - SAWC Response to the Report of the Deer Working Group. Edinburgh: The Scottish Animal Welfare Commission Secretariat.

Scottish Environment LINK. (2020). Managing Deer for Climate, Communities and Conservation. Available online at: https://www.scotlink.org/wpcontent/uploads/2020/01/Managing-Deer-for-climate-communities-andconservation-2.pdf (accessed September 22, 2021).

Scottish Government (2019). Scottish Household Survey Data Explorer. Available online at: https://scotland.shinyapps.io/sg-scottish-household-survey-dataexplorer/

Scottish Government. (2021). Scottish Government Response to the Report From the Deer Working Group on "The management of wild deer in Scotland." Edinburgh: The Scottish Government.

Vayer, V. R., Larson, L. R., Peterson, M. N., Lee, K. J., von Furstenberg, R., Choi, D. Y., et al. (2021). Diverse University students across the United States reveal promising pathways to hunter recruitment and retention. J. Wildl. Manage. 85, 1-14. doi: 10.1002/jwmg.22055

Wardropper, C. B., Dayer, A. A., Goebel, M. S., and Martin, V. Y. (2021). Conducting conservation social science surveys online. Conserv. Biol. 35, 1650-1658. doi: 10.1111/cobi.13747

Whitefield, A. C. E., McMorran, R., Paterson, J. S., and Warren, C. R. (2021). Public perceptions of deer management in Scotland: the impact of place of residence, knowledge and demographic factors. Scottish Geogr. J. 1-17. doi: $10.1080 / 14702541.2021 .1920048$

Conflict of Interest: MD works for the John Muir Trust (JMT) and is a member of Scottish Environment LINK's Deer Group, both of which are active in the policy discourse around deer management in Scotland. DH has consulted for JMT.

The remaining author declares that the research was conducted in the absence of any commercial or financial relationships that could be construed as a potential conflict of interest.

Publisher's Note: All claims expressed in this article are solely those of the authors and do not necessarily represent those of their affiliated organizations, or those of the publisher, the editors and the reviewers. Any product that may be evaluated in this article, or claim that may be made by its manufacturer, is not guaranteed or endorsed by the publisher.

Copyright (c) 2021 Hare, Daniels and Blossey. This is an open-access article distributed under the terms of the Creative Commons Attribution License (CC BY). The use, distribution or reproduction in other forums is permitted, provided the original author(s) and the copyright owner(s) are credited and that the original publication in this journal is cited, in accordance with accepted academic practice. No use, distribution or reproduction is permitted which does not comply with these terms. 